\title{
Brucella Infection Associated with Complete Atrioventricular Block
}

\author{
Meki Bilici ${ }^{1}$, Fikri Demir ${ }^{1}$, Murat Muhtar Y1lmazer ${ }^{1}$, Fatma Bozkurt², Volkan Tuzcu ${ }^{3}$ \\ ${ }^{1}$ Department of Pediatric Cardiology, Dicle University Hospital, Diyarbakır, Turkey \\ ${ }^{2}$ Department of Infectious Diseases, Dicle University Hospital, Diyarbakır, Turkey \\ ${ }^{3}$ Department of Pediatric Cardiology, Medipol University Hospital, Diyarbakır, Turkey
}

\begin{abstract}
Background: The clinical spectrum of Brucella infection is quite diverse and characterized by multi-system involvement. Patients present with myocarditis, endocarditis, or pericarditis. Infective endocarditis is the most common cardiovascular complication in patients with brucellosis. Although conduction abnormalities are seen in cases with endocarditis, they are reported very rarely in the setting of cardiac Brucella infection.
\end{abstract}

Case Report: An eight and a half-year-old male patient was referred to our clinic due to inadequate response to cotrimaxazole plus streptomycin treatment at the 15th day of admission. Although local hospital records on the patient showed a heart rate of $80 \mathrm{bpm}$, we determined a heart rate of $46 \mathrm{bpm}$. The electrocardiogram showed complete atrioventricular (AV) block. The average heart rate was determined as $48 \mathrm{bpm}$ with 24-hour Holter electrocardiogram (ECG) monitoring. The echocardiographic examination showed normal-sized heart chambers and the absence of valvular involvement. An agglutination test for brucellosis was found to be positive with a titer of $1 / 320$. High fever, arthralgia, and splenomegaly regressed following doxycycline plus rifampicin therapy, but there was no improvement in the AV block. A permanent pacemaker was implanted because of the detection of an average heart rate of $48 \mathrm{bpm}$.

Conclusion: Because cardiac failure and rhythm abnormalities are reported in the course of Brucella infection and may be associated with significant outcomes, cases with brucellosis should be evaluated carefully in terms of cardiac involvement. This report aims to draw attention to complete AV block as an extremely rare complication of Brucella infection.

Keywords: Brucella infection, atrioventricular block, myocarditis, child
Brucella infection is the most common zoonotic disease in the world and is particularly endemic in low socioeconomic populations around the Mediterranean Sea, India, and Central and South America (1). The clinical spectrum of Brucella infection is quite diverse and it is characterized by multi-system involvement. This infection can also involve the pericardium, myocardium, and endocardium. Infective endocarditis is the most common cardiovascular complication in the patients with brucellosis (1). Although conduction abnormalities are seen in cases with endocarditis, they are reported very rarely in the setting of cardiac Brucella infection (2,3). Here, we present a child diagnosed with complete atrioventricular (AV) block during the course of a Brucella infection.

\section{CASE PRESENTATION}

An eight and a half-year-old male patient was admitted to the pediatric outpatient clinic of a local hospital with complaints of high fever, arthralgia of the left ankle joint, and abdominal pain. He was diagnosed with brucellosis following determination of positive agglutination test. The patient was referred to our clinic due to inadequate response to cotrimaxazole plus streptomycin treatment at 15th day of admission. Although there was no accompanying electrocardiogram (ECG) recording, consignment note of the local hospital showed a heart rate of $80 \mathrm{bpm}$. But we determined a heart rate of $46 \mathrm{bpm}$ on admission. His body temperature was $37.9^{\circ} \mathrm{C}$ and blood pressure was $100 / 70 \mathrm{mmHg}$. His liver was palpated $2 \mathrm{~cm}$ below the costal margin, and he

Address for Correspondence: Dr. Meki Bilici, Department of Pediatric Cardiology, Dicle University 21280, Diyarbakır, Turkey

Phone: +905078562193 e-mail: drmekibilici@hotmail.com

Received: 30 December $2014 \quad$ Accepted: 21 July 2015 • DOI: 10.5152/balkanmedj.2016.140684

Available at www.balkanmedicaljournal.org 
had dullness in Traube's area. He had arthralgia but no evidence of arthritis. Of the inflammatory markers, C-Reactive protein (CRP) was $5.7 \mathrm{mg} / \mathrm{dL}$; the erythrocyte sedimentation rate was $14 \mathrm{~mm} / \mathrm{h}$. His liver function tests and troponin I level were normal. Standard 12-lead-ECG (Del Mar Reynolds Medical Pathfinder ECG system; Hertford, United Kingdom) showed complete AV block (Figure 1) and the average heart rate was $48 \mathrm{bpm}$ during 24-hour Holter ECG monitoring (Del Mar Reynolds Pathfinder Holter ECG apparatus; Hertford, United Kingdom). No sinus pause was detected. Echocardiographic (General Electric; Wauke-sha, WI, USA) examination showed normal sized heart chambers with normal systolic functions and the absence of valvular involvement. Abdominal ultrasonography (Acuson S2000TM scanner Siemens Medical Solutions; Mountain View, CA, USA) revealed splenomegaly. Agglutination test for brucellosis was found to be positive with a titer of $1 / 320$, while serologic tests for Ebstein -Barr virus, cytomegalovirus, hepatitis B virus, rubella virus, salmonella, and Borrelia burgdorferi were all negative. Repeated blood cultures were positive for
Brucella melitensis. High fever, arthralgia, and splenomegaly regressed following doxycycline plus rifampicin therapy, but there was no improvement in AV block. A permanent pacemaker was implanted because of ongoing complete AV block and average heart rate of $48 \mathrm{bpm} 30$ day after determination of AV block. Antibiotic therapy was stopped at the end of six weeks. Complete AV block persisted throughout the follow-up duration of two years.

Written informed consent was obtained from the parents of the patient presented in this report.

\section{DISCUSSION}

Brucella infection is the most common zoonosis all around the world, but especially in the Mediterranean countries. The wide clinical spectrum of the disease can lead to a delayed diagnosis (4). Although the most frequent mode of transmission of the disease is the consumption of unpasteurized milk and

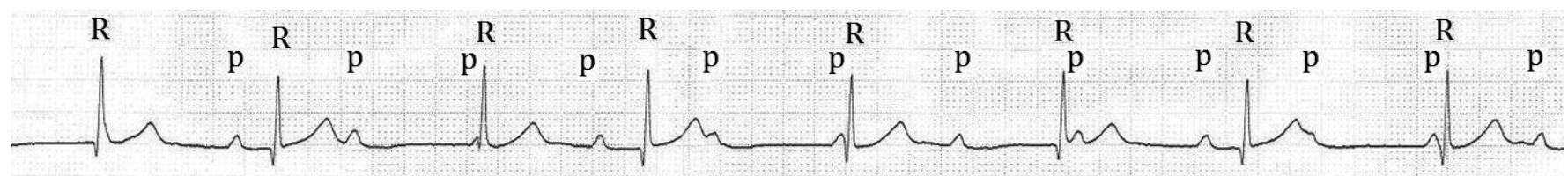
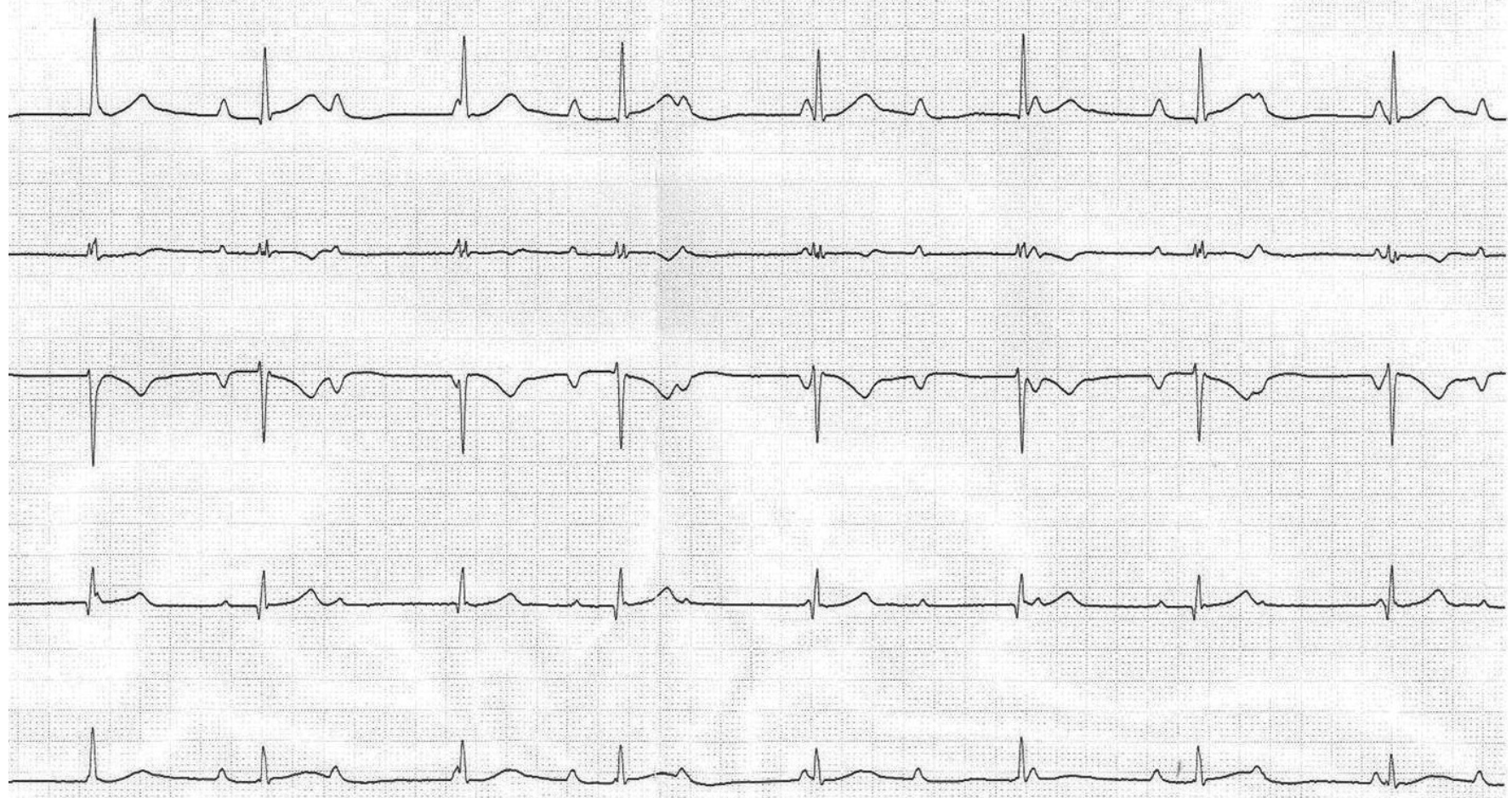

FIG. 1. Electrocardiogram showing complete atrioventricular block

$P$ : $P$ wave; $R$ : $R$ wave 
milk products, it can also be transmitted through droplet infection or direct contact with infected animals (5). Cardiovascular involvement following from Brucella infection presents most frequently as endocarditis or myocarditis $(1,4)$. It generally affects aortic valve, while mitral valve may be involved less frequently. Myocardial involvement and pericardial effusion are more frequent, especially in the setting of valvular involvement and these cases may require valvular replacement despite the long-term medical treatment (1). In a study from Spain, cardiac involvement has been identified in only $1.5 \%$ of 530 patients, whereas myocarditis and pericarditis were detected in only one case (6). Lulu et al. (7), in their study conducted in Kuwait, have detected cardiovascular involvement in 6 of 400 patients with brucellosis. However, Brucella infection rarely affects the conduction system of the heart. Electrocardiographic changes usually reflect involvement of the cardiac conduction system. Nonspecific ST-segment changes, $\mathrm{T}$ wave inversion, atrial fibrillation and complete right bundle branch block have been reported in the patients with Brucella infection $(8,9)$. Only one adult case with complete AV block following Brucella infection was reported so far (3). As the medical records of local hospital showed a normal heart rate at the beginning of the disease and no cardiac dysfunction was determined with echocardiography, we thought that complete AV block detected in our case was probably not long-standing and may be associated with recent Brucella infection. Although we had started the treatment of infection in early phase of disease, the heart block did not resolve and required permanent pacemaker. This may indicate that $\mathrm{Bru}$ cella infection may affect the conduction system with a different mechanism, such as an antigen-antibody interaction. To the best of our knowledge, our patient was the only pediatric case with complete AV block related to brucellosis.

Because cardiac failure and rhythm abnormalities are reported in the course of Brucella infection and may be associated with significant outcomes, cases with brucellosis should be evaluated carefully in terms of cardiac involvement. This report aimed to draw attention to complete AV block as an extremely rare complication of Brucella infection.

Ethics Committee Approval: N/A.

Informed Consent: Written informed consent was obtained from the parents of the patient presented in this report.
Peer-review: Externally peer-reviewed.

Author contributions: Concept - M.B., F.D., F.B., V.T.; Design M.B., F.D., F.B., V.T.; Supervision - M.B., M.M. Y., V.T.; Resource - M.B., F.D.; Materials - M.B., F.D., M.M.Y.; Data Collection and/ or Processing - M.B., M.M.Y., F.D., V.T.; Analysis and/or Interpretation - M.B., M.M.Y., F.B.; Literature Search - M.B., M.M.Y.; Writing - M.B., V.T.; Critical Reviews - F.B.,V.T

Conflict of Interest: No conflict of interest was declared by the authors.

Financial Disclosure: This work does not received any financial support.

\section{REFERENCES}

1. Abid L, Frikha Z, Kallel S, Chokri Z, Ismahen B, Amin B, et al. Brucella Myocarditis: A rare and life-threatening cardiac complication of Brucellosis. Intern Med 2012;51:901-4. [CrossRef]

2. Shah FS, Fennelly G, Weingarten-Arams J, Yang L, Glickstein J. Endocardial abscesses in children: case report and review of the literature. Clin Infect Dis 1999;29:1478-82. [CrossRef]

3. D'Agrosa MC, Lusson JR, Beytout J, Bailly P, Peycelon B, de Riberolles C, et al. Brucella endocarditis caused by reinfection of an aortic Starr valve. Apropos of a case with a favorable development after valvular replacement. Arch Mal Coeur Vaiss 1988;11:1403-7.

4. Kaya O, Avşar K, Akçam FZ. Unusual manifestations of brucellosis. Arch Med Sci 2011;7:173-5. [CrossRef]

5. Bukharie HA. Clinical features, complications and treatment outcome of Brucella infection: ten years' experience in an endemic area. Trop J Pharm Res 2009;8:303-10. [CrossRef]

6. Colmenero JD, Reguera JM, Martos F, Sánchez-De-Mora D, Delgado M, Causse M. et al. Complications associated with Brucella mellitensis infection: a study of 530 cases. Medicine (Baltimore) 1996;75:195-210. [CrossRef]

7. Lulu AR, Araj GF, Khateeb MI, Mustafa MY, Yusuf AR, Fenech FF. Human Brucellosis in Kuwait: a prospective study of 400 cases. Q J Med 1988;66:39-54.

8. Sharifkazemi MB, Moarref AR, Rezaian S, Rezaian GR. Brucella endocarditis of pseudoaneurysm of an aortic composite graft. J Cardiovasc Ultrasound 2013;21:183-5. [CrossRef]

9. Yazıc1 HU, Mert KU, Senol U, Ulus T. A case with tricuspid valve brucella endocarditis presenting with acute right heart failure Arch. Turk Kariyol Dern Ars 2012;40:364-7. [CrossRef] 